\title{
FRIEDRICH VON WIESER'S THEORY OF SOCIALISM: A MAGNIFICENT FAILURE
}

\author{
Samuel Bostaph
}

\section{Introduction}

This paper examines Friedrich von Wieser's theory of the socialist or communist planned economy. It outlines the abiding interests that impelled Wieser to present such a theory in Natural Value (1889) and in Social Economics (1914), discusses his conception of "natural value" as the basic building block of his theory and his use of that building block in his theory of the imputation of value, and it explains why his scholarly endeavor proves to be a magnificent failure.

Wieser was a pioneering member of the Austrian School of Economics, a man who taught economics at Charles University in Prague for almost twenty years and wrote Natural Value there. After leaving Prague, he assumed the economic theory chair at the University of Vienna upon Carl Menger's retirement from that chair. Wieser is usually viewed as having contributed important extensions to the work of Menger, the founding theorist of the Austrian School. Indeed, Wieser's concept of opportunity cost and his coining of the term "marginal utility" were signal contributions. On the other hand, as this paper will show, Wieser's concept of imputation and his attempt to apply it to the theory of the socialist economy is no extension of the work of Menger. It represents a return to an earlier supply-side, real cost approach to the theory of value. As such, it represents a failure to understand the radical contribution of Menger's theory of value and its application to the theory of exchange.

Just as we honor the very few successes that can be found in the history of economic theorizing, so should we honor some of the more important failures. Especially as we study magnificent failures, do we understand more deeply the successes, as well as the limitations of their extensions and applications. Wieser's theory of socialist calculation was one of those failures.

\section{Historical background}

Economic theory begins with the concept of acting man; a man who acts to substitute a state of being that he desires more for one that he desires less. The material context of economic theory proper, or "catallactics" - the theory of exchange is one of a scarcity of means. Economic theory concerns itself with constructing a theoretical framework within which scarcity can be confronted and its implications for human action can be inferred in the light of human nature, that is to say, of man as a specific type of existential being. Part of the additional task of the economist is to suggest an institutional context, i.e., a social, cultural, legal and political context within which successful economizing can be pursued. 
The task of ethical science is to discover and prescribe how man should act if he is to be truly man. On the other hand, economic theory is, to quote Mises (1966, p.10) "a science of the means to be applied for the attainment of ends;" its task is to show "how man must act if he wants to attain definite ends."

While Plato intended only the Guardians of his Republic to practice a "communism of asceticism," so that they would not be distracted from the end of maintaining the just state, all citizens of More's UTOPIA were to enjoy a "communism of abundance." In the course of the evolution of the idea of communism, Plato's ethical ideals of justice and temperance gave way to the modern striving for prosperity. Nevertheless, both Plato and More envisioned communism as an economic means to be used to achieve their ideal societies, although their respective visions are separated by almost 2000 years of civilization's development. Since More's time, almost all advocates of communism or socialism have persisted in the promise that prosperity will accompany the greater justness of their ideal society

Bearing this in mind, we cannot escape the judgment that historical attempts either to envision or to erect a just and prosperous system of communism, or of socialism, have failed. Prior to the twentieth century, there were few attempts to describe in any detail how such a communist society might operate in its materialistic dimensions, although there were a number of actual experiments, all of which eventually failed - as have almost all of those of the twentieth and twenty-first centuries. So far as early theories of communism or socialism are concerned, with very few exceptions we find only a sequence of conceptions of a social state of existence where there are no private property ownership rights and where the production of wealth involves shoving resources in one end of a black box called the factory and pulling finished goods out the other end. Of course, without private property ownership rights, decisions concerning the use of scarce material means in production for the benefit of all must be made by someone or some group - there must be a "plan" for the communist or socialist economy.

Plato placed the plan for his orderly society in the hands of the Philosopher-King and the responsibility for its implementation in the hands of the Guardians. More set his Utopia within an authoritarian and imperialistic state. Neither indicated exactly how his vision of an orderly society could be made actual. Even today, despite the widely acknowledged failures of economies whose architects referred to them as "communist" (although the term "state socialism" is a more accurate description), revolutionary cadres calling themselves socialist or communist wage continuing "wars of liberation" throughout the world. Their end purpose is to install the very sort of system indicted by both its theoretical shortcomings and its historical failures - the system whose meager fruits and conscientious brutality can be seen today in the prison states of Cuba and North Korea; systems neither just nor prosperous.

In a truly free market economy, all planning occurs at the level of the individual consumer or production unit. Prices are established in markets for the various first order goods (consumer goods), and in the higher order goods markets (producer goods markets) created by the demand for first order goods; and those prices reflect the relative scarcities of the commodities exchanged, as perceived by market participants. Market prices are the basic units of calculation that make comparable everything exchanged, thus providing a means for individual market participants to adjust their personal plans to the plans of others and enabling the calculations of profit and loss that determine the structures of production and consumption.

A socialist or communist planned economy may have markets for first order goods, but its founding rationale is the absence of private property rights-most particularly for higher order goods. Land, labour and capital are to be owned and administered by the state; hence, no true free markets for higher order goods will exist. 
Production of all goods is to be planned from the beginning to the end of each production process. But, if there are no markets or prices for higher order goods, then what is to be used as a unit of calculation? How can the heterogeneous higher order goods be made comparable with one another for planning purposes? Some early socialist theorists - most notably Marx and Engels - thought they had found such a unit in the concept of the hour of "socially necessary labor time." As Engels put it in Anti-Duehring:

Society can simply calculate how many hours of labour are contained in a steam-engine, a bushel of wheat of the last harvest, or a hundred square yards of cloth of a certain quality....society will not assign values to products. It will not express the simple fact that the hundred square yards of cloth have required for their production, say, a thousand hours of labour in the oblique and meaningless way, stating that they have the value of a thousand hours of labour. It is true that even then it will still be necessary for society to know how much labour each article of consumption requires for its production. It will have to arrange its plan of production in accordance with its means of production, which includes, in particular, its labour-power. The useful effects of the various articles of consumption, compared with one another and with the quantities of labour required for their production, will in the end determine the plan. People will be able to manage everything very simply, without the intervention of much-vaunted "value" (see Steele, 1981, p. 12).

Engels's attempt to evade the value implications of expressing higher order goods in labor hour equivalents does not affect his purpose in so expressing them. That purpose was to use the labour hour as a unit of calculation in a plan of production. The exposure of the fallacy of the labour theory of value by Austrian School theorists, and others, seemingly left Engels and other socialist theorists without a basic building block for their theories.

Early in the twentieth century, the "socialist calculation debate," initiated by Mises in 1920, forced socialist and communist theorists to confront this deficiency. Men such as Lange, Taylor, Dickinson and Dobb seriously addressed the problem of planning a socialist or communist economy. The results were models of socialism that claimed to mathematically mimic a free market economy without possessing the basic structure of that economy, the free markets that provide the producer prices that constitute the means for economic calculation. These models were met by the devastating critiques of Mises and Hayek in the 1920s and 1930s - critiques whose accuracy and cogency were borne out by the planning deficiencies and the consequent poverty of the Soviet and Eastern European planned economies and their final collapse less than twenty years ago (see Mises, 1920, 1936; Hayek, 1935; Lange and Taylor, 1938 and Hayek, 1948).

This is where we must recognize the distinctiveness of Wieser's attempt to construct a theory of socialist or communist calculation. In contrast with most nineteenth century theorists of socialism, Wieser recognized that the labour theory of value was fallacious and, consequently, that the key vulnerability of any planned economy would be the need for an alternative basic unit of economic calculation. If values cannot be expressed in hours of labour, then labour hours cannot be used as basic units of calculation in either production or distribution. Production processes become arbitrary or ad hoc, as does the definition of successful planning or of social welfare. Recognizing this, Wieser attempted to supply a basic unit of calculation for socialism by what he termed the "unempirical fiction" of a unit of "natural value."

Solving the calculation problem was the task set for himself by Wieser and his proposed solution - although ingenious and using the tools of modern economic value theory - is the "magnificent failure" of the title of this paper. In order to understand why Wieser set himself this task, it is useful to review some key points made in his last great treatise - The Law of Power, published shortly before his death in 1926. Then, we may examine Wieser's magnificent failure itself. 


\section{The Law of Power}

Wieser viewed The Law of Power as his magnum opus, a sociological treatise that completed a lifetime of study and reflection on history, law, economics and political theory. Because the book is almost totally without references, it must be read and appreciated as the magisterial pronouncements of a widely-read and learned man. As he explains in the preface, Wieser had been driven to study history "by an unquenchable thirst" since his boyhood. The central meaning of history finally came to him as a result of his attempt to understand the World War in the context of the history of civilization. His foundational conclusion appears (1983, p. 37) at the beginning of The Law of Power: "The whole social entity is governed by power, this being the highest value peoples aspire to and by which they are counted, weighed, and judged;" and (1983, p. 3), "social power...means command over the minds of the members of society." The key question is always, "Who rules?" Society itself is (1983, p. 45) hierarchical, claims Wieser, with human dregs on the bottom, passive masses next, reflective followers next, active followers next, and the leading class on top.

As the political and social expression of the common people, Wieser asserts that the success of liberalism led it to seek power even as "freedom" was voiced as its creed. Ironically, liberal economic legislation (1983, p. 302) put the weak proletariat and bourgeois craftsmen at the mercy of exploitative businessmen, who used the language of freedom to disguise their predations. Entrepreneurs claim to act for the general interest, but their incentive is really the enjoyment of personal power, Wieser observes. This is what (1983, p. 65) "turns them indifferent to the imposition of coercion on their collaborators and competitors and the associated large sacrifice demanded of them." With the rise of manufacturing industries and production on a large scale, entrepreneurs became masters of hundreds and thousands of workers while (1983, p. 257) "impairing or ruining the economic position of millions of bourgeois craftsmen," crowding out small-scale enterprises and increasing business concentration. As capitalist concentration grows and the manufacturing entrepreneur becomes a leader with social power, he (1983, p. 310) "guides [demand] into certain channels" until "demand adjusts to the conditions of production.... and in the end [it] is transformed into following."

In the course of his discussion of the growing inequality in the distribution of power, Wieser notes a growing social, political and economic stratification. Growing inequality in the distribution of wealth and income means that the preferences of the wealthy, as expressed in demand functions and exchange values, stratify demanders in commodity markets. Instead of each individual's preferences counting the same as everyone else's, the preferences of the wealthy rule and the unequal power of demanders in commodity markets reflects the inequality in the political and social realms.

At the stage of cartels and trusts, the firm is no longer (1983, p. 311) a "free leadership organ," it is "an authoritarian leadership organ." Early in the book (1983, p. $41)$, Wieser had given the opinion that if entrepreneurs wielded their power without restraint, they could "do violence to the economy." Near the end (1983, p. 357) he expresses agreement with Marx's identification of the "shocks caused by crises and social upheaval which are concomitants of the activities carried out by the capitalist enterprise" and opines that socialist observers of the capitalist enterprise applaud "its accomplishments as such, which through irresistible economic concentration move decentralized private economic decision-making closer to the centralized system of the future state...." This opinion extends his earlier (1983, p. 88) expressed view, "Should one day things change in such a fashion that the tech- 
nique and organization of enterprises are no longer compatible with private property, then socialism could claim success." Given these views, it is not surprising that Wieser explored the question of how a socialist or communist society might be structured in his earlier works - notably in Natural Value and Social Economics.

Two themes pervade both Natural Value and Social Economics: one is that economic calculation in "natural values" would make the socialist economy possible; the other is that such an economy would eliminate the stratification of demanders in markets, and the consequent lower total social utility, that exists in the capitalist economy. The latter effect would be the result of eliminating market-determined prices, where the use of money sets exchange values that express the disparate power of stratified society. An earlier paper argues (see Bostaph, 2003, pp. 11-16) that Wieser's "stratification" argument is founded on an incomplete understanding of the market pricing process. Setting that critique aside for now, let us examine the solutions that Wieser presented in his earlier books to the problems he later attributed to "power" in his grand sociological treatise on The Law of Power. As he remarked (1983, p. 123) in that latter work, "Until now, social decision-making has never and nowhere achieved the degree of unity found in the realm of personal decisions. Never and nowhere has it therefore been devoted to the maximization of social welfare in the way personal decisions have shaped personal survival and growth. Social action...has not been devised from the top in accordance with a governing principle of higher social utility..." To try to envision such a state of social action was the governing principle of Natural Value, while Social Economics extended the analysis to include the role of power in the actual social, state and world economies. The rest of this paper mainly will be confined to the vision articulated in Natural Value, because it is the foundational one.

\section{Natural Value}

In the "Author's Preface" to Natural Value, Wieser states (1971, p. 30) that "value is the essence of things in economics" and expresses the view that the theory of Menger is the more deeply informative of the new theories based on utility. Wieser offers his own work as an extension of Menger's and an attempt (1971, p. 35) "to exhaust the entire sphere of the phenomena of value...."

Book I takes the standpoint of the individual valuing person and argues: (1) that want rather than utility (in the sense of objective 'useful' characteristics) is the source of the value of goods; (2) that the marginal satisfaction or "marginal utility" obtained from the use of any particular unit of a good used to satisfy a want declines with each additional unit's use within a given period of want; (3) that the units of a limited supply of a good that can satisfy several competing wants at a point in time should be distributed in such a way that the marginal utility in each competing use is the same; and (4) that a supply of goods should be distributed over a period of time such that the utility of their use is maximized. The general rule to be applied is (1971, p. 15) "that in all employment [of goods] as low a marginal utility be reached as is possible without necessitating the loss, in another employment, of a higher utility." Here we find Wieser's justly celebrated concept of opportunity cost first introduced in an early paper presented to Karl Knies's seminar in Heidelberg in 1876, thirteen years before the publication of Natural Value. We find as well Wieser's systematic use of the term "marginal utility" ("grenznutzen"), a term which he coined to describe the value of the nth unit of any good (see Wieser, 1876, p. 216).

It is in Book II that Wieser introduces his concept of "natural value." He does so in chapter VI, the avowed aim of which is indicated in the analytical table of con- 
tents of the entire work as (1971, p. 39) "to find what, among our forms of value, would continue in a perfect or communist state, and so to find the permanent basis of all economic life." Book II itself is introduced with the stated intent (1971, p. 36) of describing "...natural value, i.e. value as we should find it in a community at a high stage of development carrying on its economic life without price or exchange." Chapter VI of Book II is the key turning point of the whole argument for it is at the beginning of that chapter that Wieser gives us his definition of natural value. He argues (1971, p. 60) that in a communist community, goods would have value just as they do in any other community because human wants and the means insufficient to satisfy those wants are universal. All goods "would rank in value according to the relation in which the available stocks stood to the demand; and that relation would express itself finally in the marginal utility. Social supply and demand, or amount of goods and utility socially compared with one another, would decide value." It is "that value which arises from the social relation between amount of goods and utility, or value as it would exist in the communist state, we shall henceforth call 'Natural Value'."

Wieser's brief argument in support of his definition of "natural value" also is critiqued at length in the same paper mentioned earlier (see Bostaph, 2003, pp. 5-16), as well as in a biographical essay included in a collection of essays on primary figures in the history of the Austrian School, edited by Horwitz and soon to be published by Elgar. To be brief, it is argued that in Wieser's own explanation of the marginal utility theory of value, values are the result of evaluation by an individual person and the law of marginal utility applies only to the evaluation process of such an individual. Nowhere in his writings does Wieser provide an explanation of how individual (subjective) marginal utility calculations can come to be socially objectified in the form of "natural value." "Natural value" is incoherent if it is meant as "social" marginal utility. The entire argument of the rest of the book fails with the attempt to socially objectify "natural value" into a means of calculation. But, given that conclusion, let us see why Wieser's failure might be deemed "magnificent."

Wieser's purpose appears to be to create (1971, p. 27) a "measuring scale for the valuation of goods" that is separate from that of exchange value or price. He wishes to do so because he regards the exchange values established in an exchange economy as imperfectly reflective of marginal utilities. Their imperfection is rooted in the distorting influences of (1971, pp. 61-62) "human imperfection, by error, fraud, force, chance...the existence of private property, and by the differences between the rich and poor...." The latter difference introduces the element of purchasing power, in addition to marginal utility, as determinant of exchange value. Pure marginal utilities would express "natural value" and provide a means of calculation for the socialist or communist economy that would make possible the maximum total social utility in the ordering of production and consumption. As he puts it (1971, p. 61), "We shall ask ourselves what productive instruments would be likely to obtain value in a communistic state, whether labour alone, or also land and capital; in what measure they would obtain value; whether there is a natural rent from land and a natural interest on capital-and so on through all the circumstances of production, till we arrive at the question of cost value and its natural measurement."

Although he is critical of the labour theory of value in Chapter VII, and of its use for calculation in a socialist society, Wieser is actually attempting to use the same supply-side approach in the simple socialist economy of Natural Value by conceiving of a unit of value (the "natural value" of the title) as a supply-side means of calculation for socialism - a substitute for the concept of the hour of "socially necessary labour time." From the expression of the value of first order goods in natural 
value units, Wieser would then impute the value of higher order goods. His argument for the imputation of "natural value" from lower to higher order goods is the subject of Book III. It involves an attempted logical process of "conversion" - a backward sort of inferring from conclusion to premises that assumes that the whole of the conclusion is distributed to the premises.

\section{Imputation}

If the "natural value" unit is to be used as a means of calculation in a socialist economy, it must be used as the means of measurement to plan the use of higher order goods to produce those of lower orders. This means that the values of all goods must be expressed in units of "natural value," and then their production relationships be so ordered that an array of first order goods can be produced that will provide the maximum social utility of all possible arrays that could be produced. Wieser had envisioned just such an arrangement in his Heidelberg paper of 1876. There, he generalized (1994, p. 224) that "...from the value of the last product to be produced in each category of goods, the value of the productive good is determined, which is then reflected in all the other categories of goods." The imputed values of higher order goods thus link all categories of the first order goods they can be used to produce into a complex of mutually determining and determined values. It is not difficult to see an early non-mathematical presentation of the concept of a (timeless) general equilibrium in this conception.

Of course, the basic question is: How is the imputation of value to be done? Wieser's mentor, Menger, had described (1976, pp. 162-165) the imputation of value as a process of asking how much value would be lost in first order goods production if one unit of a higher order good needed for that production was to be removed from use. The result would tell you the value of the unit of the higher order good. Menger's description is of a dynamic process set in real time, where the answer concerns only one unit of one higher order good. It is not a description of the determination of distributive shares of higher order goods in the value of the first order goods they are used to produce. In contrast, Wieser's interest lies in explaining the values of all units of all higher order goods used in production so that their use might be rationalized so as to produce the greatest social utility in a planned economy. He attempts to show how the value of first order goods is distributed among all higher order goods used in their production in a general equilibrium model. This model is envisioned as a system of simultaneous equations that would describe the value relations among all goods in all orders and that could be manipulated to achieve the maximum social utility. In the first part of his Social Economics (1967, p. 51), Wieser assumes a planner who technically organizes production and distribution so that no productive resource can be shifted from one use to another without a diminution in the total utility of the consumption of output. Unfortunately, he only can make this assumption both in natural value and in Social Economics by ignoring Menger's dynamic approach and restricted focus, as well as by dropping the marginal utility theory of value, as we shall soon see.

Wieser illustrates his conception of imputation with an example set of three simultaneous linear and homogeneous equations with three unknown variables. Each equation is asserted to express a combination of factors of production on the left side (expressed as the addition of two of the three variables, each of which is multiplied by a constant) and the value of the returns on the right side (expressed as a constant). Solution of the set is to provide values for the variables, which can then be substituted into the left sides of the equations to provide the respective amounts of "the total value of the return" to be imputed to each of the cooperating 
productive factors. Given the general equilibrium context of Wieser's argument, the imputation of value of first order goods to all higher order goods in an economy would lay bare the interconnections of value of all goods of all orders in the model economy. Of course, that is Wieser's purpose because he states (1971, pp. 95-6) that he wishes to engage in "consideration of production as a whole," so that government might evaluate the total employment of all resources to produce the greatest possible total value. His view of imputation as the solution of a public set of simultaneous equations that distributes the "total value of the return" among the cooperating factors of production leads him to surmise that national economic planning is not only possible, but it would provide a greater possible total output value than disaggregated individual planning. The aspiration he expressed in The Law of Power to provide the degree of unity to social decision-making that is possible for personal decision-making would be realized.

Unfortunately for his argument, Wieser's example equation set is ambiguous with respect to the meanings of the variables and constants in the equations. Nevertheless, whether values or quantities of goods are assigned as the meanings of the constants or variables on the left side of the equations, there are several problems in this approach. First, there is no explanation of how subjective values could be objectified in such equations. If they can't be objectified, they can't be used in planning. The ambiguity of Wieser's concept of "natural value" fatally undermines its grand extension in the imputation of value. Second, the equations appear to show fixed-proportion production functions, a simple form of what was later used in the Linear Programming approach to production theory. This approach avoids the question of how such proportions come to be determined. Also, fixed-proportion production functions are in conflict with the temporal causal relation between variations in specific amounts of specific productive inputs and the resulting variations in the total value of output, which is the very relation that Menger's dynamic theory of the imputation of value assumed, as well as being a requirement for determining marginal utilities. Third, the equations assume that the production goods whose fixed proportions are summarized by the equations are available in just those proportions, without any explanation of how production units could obtain resources in just those relative amounts.

One obvious explanation for Wieser's procedure is that he used the accounting distribution of revenue from final sales among the factors responsible for the production of the goods sold as a template for his theory of the imputation of value. But, there is a vast difference between the dynamics of value comparisons or of value imputation and the statics of accounting. Such an accounting distribution can be done for any particular firm, using historical quantities and prices. This is the purpose of the firm's income statement. But the determination of the expected value of an individual first order good, and the imputation of that expected value to a higher order good is only a first step in a process of determining what higher order goods to use and in what combinations to produce first order goods. For the latter determination to be made, price comparisons are required. The expected prices of first order goods in the markets for those goods must be compared with the actual and expected prices of higher order goods and their various possible combinations in the production of the first order goods in question. The context of dynamic exchange markets is one in which firms compete for the services of higher order goods in anticipation of the profits to be obtained from the expected revenues from the expected level of sales of first order goods at prices expected to prevail in the future. The actual prices of higher order goods are constantly evaluated and re-evaluated with respect to expected future prices of all goods in a production chain leading to the first order goods of the future. In brief, subjective value relati- 
ons that result in marginal utility comparisons are not the relations for the profit and loss calculations that determine the structure of production and the remuneration of the factors. It is those latter calculations that utilize pricing information and result in the organization of specific amounts of higher order goods to produce first order goods and determine the actual structure of production. Economic calculation requires markets and market prices. The means that provide unity to personal decision-making marginal utilities - are not the same means - markets and market prices - that provide unity to a social economy.

\section{Conclusion}

Wieser's attempt to extend and then apply the new marginal value theory of Menger to the problem of the organization of the communist economy is ambitious and possesses intellectual grandeur, but must be judged a failure. Early in his career, Wieser developed the opportunity cost concept, linked it with the concept of the imputation of value and used both to develop the notion of a link between all goods in a social economy. His critical view of the fruits of liberalism in the market economy of his day impelled him to conceive of an economy where production could be planned without markets and without the consequent market prices that he believed to be distorted by an unequal distribution of income and wealth. But, he was led to a magnificent failure in this vision of a successful, planned, communist economy by three errors in his extension of Menger's value theory: 1) His attempt to use subjective values as surrogates for objective units of calculation - the "natural values" of his model - seeks to make objective and public what is subjective and personal, but fails through the ambiguity of his explanation. 2) His consequent attempt to quantify subjective value relations through imputation for planning purposes substitutes the statics of a general equilibrium analysis for the dynamics of Menger's vision of the market process, and even drops the very concept of marginal utility itself - the wellspring of the subjective value theory. 3) Most importantly, his departure from Menger's recognition that exchange relations are the center around which all calculations of value revolve in a social economy sets Wieser's ideal economy adrift into a sea of arbitrary production and distribution relations. Without exchange relations in markets, there are no prices. Without prices, economic calculation in a social economy is not possible, as Ludwig von Mises subsequently and decisively argued in 1920.

Wieser's magnificent failure is instructive. In studying it, we understand more thoroughly the basic concepts found in Menger's Principles and the implications of the theory of the market process that Menger founded. Especially do we understand more thoroughly what that theory cannot be used to do. If there is to be found a basis or foundation for planning in the socialist or communist economy, it is not to be found in the theory of subjective value at least not as Wieser attempted to use that theory.

References

Bostaph, S. (2003), "Wieser on Economic Calculation Under Socialism." The Quarterly Journal of Austrian Economics, 6(2), pp. 3-34.

Hayek, F. A. (1935), "The Nature and History of the Problem," and "The Present State of the Debate," in Hayek, F. A., ed., Collectivistic Economic Planning. London: Routledge and Kegan Paul.

(1940, 1972), "Socialist Calculation III: The Competitive 'Solution,'” in Individualism and Economic Order. Chicago, Regnery. 
Lange, O., Taylor, F. M. $(1938,1964)$, On the Economic Theory of Socialism. New York: McGraw-Hill.

Menger, C. $(1871,1976)$, Principles of Economics. New York: NYU Press.

Mises, L. von $(1920,1935)$, "Economic Calculation in the Socialist Commonwealth," in Hayek, F. A., ed., Collectivist Economic Planning. London: Routledge and Kegan Paul. (1936, 1951), Socialism. London: Jonathan Cape. (1949, 1966), Human Action, 3rd Ed. Chicago: Regnery.

Steele, D. R. (1981), "Posing the Problem: The Impossibility of Economic Calculation under Socialism." The Journal of Libertarian Studies, 5 (1), pp. 7-22.

Wieser, F. von $(1893,1971)$, Natural Value. New York: Augustus M. Kelley. $(1876,1994)$, On the Relationship of Cost to Value, translated and reprinted in Israel by M. Kirzner, Classics in Austrian Economic. London: William Pickering. $(1914,1967)$, Social Economics. New York: Augustus M. Kelly. (1926, 1983), The Law of Power. Lincoln: University of Nebraska - Lincoln.

\title{
FRIEDRICH VON WIESERS'S THEORY OF SOCIALISM: A MAGNIFICENT FAILURE
}

Samuel Bostaph, University of Dallas, College of Business, 1845 East Northgate Drive (e-mail:bostaph@udallas.edu).

\begin{abstract}
:
This paper examines Friedrich von Wieser's theory of the socialist or communist planned economy. It identifies in Wieser's Law of Power (1926) the abiding interests that stimulated his attempt to use Carl Menger's theory of subjective value to present a theory of socialism, first in Natural Value (1889) and later in Social Economics (1914). It discusses his conception of a unit of marginal utility, or "natural value," as the basic unit of economic calculation in his imputation theory and his use of that building block in his consequent theory of production and distribution in a socialist economy. Lastly, it argues that Wieser's theory attempts to socially objectify subjective values and is actually a return to a pre-Mengerian supply-side, real cost approach to the theory of value. Wieser's theory of economic calculation under socialism thus represents a failure to understand the radical contribution of Menger's value theory to the theory of exchange.
\end{abstract}

Keywords: Wieser; economic calculation; marginal utility; imputation theory

JEL Classifications: B130; B140; P210 